\title{
Microscopic and submicroscopic Plasmodium infections in indigenous and non-indigenous communities in Colombia.
}

\author{
Jehidys Montiel \\ Universidad de Antioquia \\ Lina M. Zuluaga \\ Universidad de Antioquia \\ Daniel C. Aguirre \\ Universidad de Antioquia \\ Cesar Segura \\ Universidad de Antioquia \\ Alberto Tobon-Castaño \\ Universidad de Antioquia \\ Ana M Vasquez ( $\square$ amaria.vasquez@udea.edu.co) \\ Universidad de Antioquia https://orcid.org/0000-0001-9418-3298
}

\section{Research}

Keywords: malaria, indigenous communities, asymptomatic infections, submicroscopic infections

Posted Date: December 3rd, 2019

DOI: https://doi.org/10.21203/rs.2.17952/v1

License: (c) (i) This work is licensed under a Creative Commons Attribution 4.0 International License. Read Full License

Version of Record: A version of this preprint was published at Malaria Journal on April 16th, 2020. See the published version at https://doi.org/10.1186/s12936-020-03226-4. 


\section{Abstract}

Background The indigenous population is considered a highly susceptible group to malaria becouse they usually live in areas with high Anopheles exposure and poverty, and have low access to health services. There is a great diversity of indigenous communities in Colombia living in malaria-endemic areas; however, the burden of infection in these populations has not extensively studied. This study aimed to determine the prevalence of Plasmodium infections in indigenous and non-indigenous communities in two malaria-endemic areas in Colombia.

Methods A Community-based cross-sectional survey was conducted in seven villages of Turbo and El Bagre municipalities; three of these villages were indigenous communities. All inhabitants of all ages that were willing to participate were included. Sociodemographic and clinical data were recorded as well as household information. The parasitological diagnosis was performed by microscopy and nested PCR. The prevalence of microscopy and submicroscopic infection was estimated. An adjusted GEE model was used to explore risk factors associated with the infection.

Results Among 713 participants, $60.1 \%$ were from indigenous communities. Plasmodium spp. was detected in 30 subjects (4.2\%, Cl 95\% 2.95.9); from those, 29 were in the indigenous population, $47 \%$ of infections were afebrile, and most of them submicroscopic (10/14). Microscopic and submicroscopic prevalence was $2.5 \%(\mathrm{Cl} 95 \%$ 1.6-3.9) and 1.7\% (Cl 95\% 0.9-2.9) respectively. In El Bagre, all infections occurred in indigenous participants (3.9\%, $\mathrm{Cl} 95 \%$ 2.2-7.1), and $81 \%$ were submicroscopic. By contrast, in Turbo, the highest prevalence occurred in indigenous people (11.5\%; $\mathrm{Cl} 95 \%$ : 7.3-17.5), but $88.8 \%$ were microscopic. Living in an indigenous population increased the incidence rate of infection compared with a non-indigenous population (IRR 19.4; Cl 95\% 2.3-166.7).

Conclusion There is a high proportion of Plasmodium infection in indigenous communities. A substantial proportion of asymptomatic and submicroscopic carriers were detected. The identification of these infections, not only in indigenous but also in the non-indigenous population, as well as their associated factors, could help to implement specific malaria strategies for each context.

\section{Introduction}

Although significant advances have been made towards malaria elimination in several endemic countries, malaria remains a significant public health problem [1]; the World Malaria Report 2018 estimated that the global malaria burden was around 219 million reported cases and 435000 deaths worldwide [2]. Besides, the situation in the Americas comes up with further challenges for control and malaria elimination, given the high proportion of cases by Plasmodium vivax [3]. Particularly in Colombia, the number of malaria cases officially reported in 2018 was 63143 , being Chocó, Nariño, Cordoba, and Antioquia, the departments with the highest number of malaria cases $(27.0 \%, 20.6 \%, 15.6 \%$, and $8.8 \%$ respectively [4].

In the Americas region, the indigenous population is considered one of the most vulnerable groups to suffer malaria. The highest vulnerability can be explained not only because they live in areas with a high Anopheles bite exposure, but also because they have high poverty rates and usually do not have access to diagnostic and treatment services [5]. Information about the health of these populations is not always collected, so their risk is not well understood, but in general it is known indigenous communities have poor health indicators as compared to nonindigenous populations, including morbidity and mortality due to transmissible diseases, child undernutrition, infant mortality rates, and years of potential life lost [6].

In Colombia, $3.4 \%$ of the population is indigenous, and there are around 710 indigenous communities located in 27 departments [7], many of them living in malaria-endemic regions. Between 2009 to 2014 years, $75.8 \%$ of the Colombian indigenous population was at risk of being infected by any microorganism, where Plasmodium spp caused $46.7 \%$ of the total infections [8]. Unfortunately, there are few studies in the indigenous population, so that the risk is not well understood. Only eight of the Twenty-one endemic countries of the Americas Region reported cases of ethnic groups and indigenous peoples in 2014 [5]. Without adequate data, it is difficult to follow up on malaria trends, recognize the risk factors in these communities, and establish malaria control strategies. In Colombia, the majority of malaria cases occurs at the pacific coast and amazon regions and affects mainly Afro-Colombian and indigenous populations [1, 9], during 2018, 62141 cases of malaria were reported, of these, 14714 (23.7\%) were in the indigenous population [10]. It has also been reported autochthonous malaria transmission mainly among indigenous communities in Chocó (Pacific coast) [11].

Antioquia was one of the departments with the highest malaria prevalence in Colombia for many years. However, since 2008, the number of cases has decreased markedly from 20511 cases for that year to 4971 in 2017 [12]. This was due to several malaria control strategies implemented between 2007 to 2010, as vector control activities, strengthen of diagnosis network, insecticide-treated bed nets (ITNs) distribution, and chemoprophylaxis. Despite a reduction, a significant proportion of malaria cases is related to gold-mining activities, which play an important role in the maintenance of malaria transmission and are considered as an important barrier to malaria elimination [13]. Like miners, indigenous populations are also considered as an important reservoir of malaria transmission. Unfortunately, these populations have been scarcely studied, and there is not enough information about the Plasmodium prevalence in them.

Page 2/16 
One of the main challenges for the success of malaria control programs is the early diagnosis and treatment, not only for symptomatic but also for asymptomatic infections, which represent a silent reservoir of parasites [14]. Compare to patients with acute malaria disease, who generally seek treatment in health facilities, people with low-density infections that often are asymptomatic, do not seek medical attention or antimalarial treatment $[15,16]$. These infections can contribute to local transmission in an endemic region [17]. It has been reported that in Peru, $50 \%$ of $P$. falciparum and $22 \%$ of $P$. vivax asymptomatic infections can harbor gametocytes [18]; similarly, in Colombia, $57 \%$ of the samples from asymptomatic volunteers were infective to mosquitoes [19].

In Colombia, the prevalence of low-density infections by Plasmodium has been previously explored, finding frequencies of the infection in general population from $2 \%$ to $15 \%$, most of these infections were submicroscopic [20-22] and in pregnant women from $1.1 \%$ in peripheral to a $2.1 \%$ in placental blood [23]. In Urabá Region in Colombia, the prevalence of asymptomatic infections detected by PCR was 2.6\% [24]. Together these studies suggest that in low endemic settings such as Colombia, molecular tests are more useful than microscopy to detect this kind of infection [25-27].

Most of the studies about low-density infections in Colombia have been conducted in the general population and pregnant women, but there are not reports in special populations as indigenous people. We aimed to determine the prevalence of microscopic and submicroscopic Plasmodium infections in indigenous and non-indigenous communities in two malaria-endemic areas in Antioquia-Colombia and to explore the associated factors to the Plasmodium infections.

\section{Methods}

\section{Study design}

A cross-sectional study was conducted in seven endemic malaria villages of Turbo and El Bagre towns between November 2016 to June 2017. Villages in every town were selected based on the historical records of malaria cases, and the accessibility for field staff. Three of these villages were indigenous communities (Los Aguacates and Los Almendros in El Bagre and Arqua in Turbo).

\section{Study sites description}

The two towns selected for this study are located in the Antioquia department. Turbo ( $\left.8^{\circ} 05^{\prime} 42^{\prime \prime} \mathrm{N}, 76^{\circ} 44^{\prime} 123^{\prime \prime}\right)$ is located in the Uraba region of Colombia (Figure 1), has an area of $3055 \mathrm{~m}^{2}$, an altitude of 2 meters above sea level and an average temperature of $28^{\circ} \mathrm{C}$. The main economic activity is banana production and export $[28,29]$. El Bagre $\left(7^{\circ} 35^{\prime} 25^{\prime \prime} \mathrm{N}, 74^{\circ} 48^{\prime} 27^{\prime \prime}\right)$, is located in the Bajo Cauca region of Colombia (Figure 1)," has an area of $1563 \mathrm{~m}^{2}$, an average temperature of $37^{\circ} \mathrm{C}$ and an altitude of 50 meters above sea level [29, 30]. The main economic activity is gold mining. The annual parasite index (parasite incidence per 1,000 population) reported for 2017 was 0.77 in Turbo and 21.29 in El Bagre, in both, P. vivax was the predominated species [12].

\section{Study population and data and sample collection}

A census was carried out in each village to know the number of houses and people; all individuals were invited to participate in the study. Individual and household data regarding sociodemographic, self-report of previous malaria episodes, and characteristics of the household were collected. Axillary temperature was measured, and $6 \mathrm{~mL}$ of whole blood was collected by venipuncture in tubes with anticoagulant EDTA (BD Vacutainer, BD Franklin Lakes, USA). Samples were stored at $4^{\circ} \mathrm{C}$ until processing at the laboratory of the local hospital in each municipality. The sample was used to perform diagnosis by microscopy using thick and thin blood smears the molecular diagnosis from blood spots on Whatman filter paper \#3 (Fisher, Ref 1003-917), and to measure hemoglobin levels using by a HemoCue (Hb 201+, Lake Forest, California).

\section{Laboratory procedures}

\section{Conventional microscopy}

Field-stained thick and thin blood slides were read in the field by an expert microbiologist according to national guidelines [31]. Parasitaemia was estimated against 200 leukocytes (assuming a standard value of 8,000 leukocytes/ $\mu \mathrm{L}$ of blood) and was expressed as parasites/ $\mu \mathrm{L}(\mathrm{p} /$ $\mu \mathrm{L}$ ). A sample was considered negative if, after the examination of 200 microscopic fields at 100x magnification, no parasites were observed. As a quality control, a second reading was performed in all PCR positives samples and 10\% of negative ones. Discordant results were solved by a third reading. All participants with positive thick smear received anti-malarial treatment according to national guidelines [31]. 


\section{Molecular diagnostic}

DNA was extracted from a half blood-spot filter (approximately $30 \mu \mathrm{L}$ of blood) using the QIAamp DNA Mini Kit following the manufacturer's recommendations (QIAGEN, Germany). Nested PCR was performed as a two-step procedure following the protocol described by Singh et al. [32]. Amplification products were resolved in a 1.5\% agarose gel stained with GelRed ${ }^{\text {TM }}$ (Biotium, United States) and visualized under UV light. This protocol consists of a universal PCR that detects and amplifies a region of $18 \mathrm{~S}$ ribosomal gene from the Plasmodium genus. Positive samples for Plasmodium spp were processed by using species-specific primers for $P$. falciparum and $P$. vivax.

\section{Ethical considerations}

This study was reviewed and approved by the Ethics Committee at Medicine school, Universidad de Antioquia in Medellín, Colombia (Record 011 dated 28 July 2016). Before to start the fieldwork, permission from community leaders was approved in each village. Signed informed consent was obtained before the interview and blood sampling for all participants. In the case of individuals $<18$ years old, an additional informed consent from parents or legal guardians was also obtained..

\section{Statistical analysis}

All data from questionnaires and forms were entered into a Microsoft Access database, and statistical analyses were conducted in STATA 14 (StataCorp. 2015. Stata Statistical Software: Release 14. College Station, TX: StataCorp LP). A description of the population was carried out for both, individual (anemia, sex, age group, occupation, residence time in endemic region, number of malaria episodes, malaria in the previous year, municipality, use of mosquito nets) and housing factors (inhabitants per household, draining of stagnant water, access to electricity, water and sewer system). Frequencies were expressed as numbers and percentages for qualitative variables and medians with the interquartile range for the quantitative ones. The global prevalence of Plasmodium infection was estimated by diagnostic tests (microscopy and nPCR), locality (Turbo and El Bagre), and type of community (indigenous and non-indigenous communities). 95\% confidence intervals (Cl) are shown for each estimation. A generalized estimating equation (GEE) model [33] was used to handle the nested structure of sampled data (713 individuals nested within 212 households), GEE model was fitted for a Poisson family with a logarithmic link and an exchangeable correlation. Crude (IRR) and adjusted (aIRR) Incident Rate Ratios (by occupation and malaria in the previous year) were calculated for the Plasmodium infection (outcome) with $95 \%$ confidence intervals for each factor.

\section{Results}

\section{Socio-demographic and household characteristics}

In this study, 713 subjects from 212 houses were enrolled in seven villages of two municipalities in Antioquia department (Figure 1). El Bagre town had more indigenous people $(n=276 ; 38.7 \%)$ than Turbo $(n=157 ; 22.0 \%)$. The proportion of Plasmodium infection in both municipalities was higher in indigenous communities than in non-indigenous communities $(6.69 \%$ vs. $0.36 \%)$.

The characteristics of participants, according to the residence in the indigenous communities, are shown in Table 1. There was a slightly higher proportion of anemia in non-indigenous people (15.4\%) compared to indigenous (12.7\%). The gender and age group distribution were similar in both groups, and the majority of people have lived in an endemic malaria region for more than four years (72.5\% and $75 \%$ in non-indigenous and indigenous communities respectively). Most of the indigenous people lived in houses with more than five people (59.1\%) and had animals in their homes (97\%). Additionally, a high proportion of them did not drain standing water in their homes (93\%), and $34 \%$ had no access to electricity.

\section{Plasmodium infections prevalence}

The overall prevalence of Plasmodium spp infection was $4.21 \%(95 \% \mathrm{Cl} 2.95 \%-5.96 \%), 60 \%$ of these infections were detected by microscopy, and $P$. vivax was the predominant species (3.09\%; $95 \% \mathrm{Cl} 2.04 \%-4.65 \%)$. The prevalence of infection was higher in Turbo compared to El Bagre town $(5.67 \%, 95 \% \mathrm{Cl} 3.64 \%-8.73 \%$ versus $2.91 \%$, 95\% $\mathrm{Cl} 1.62 \%-5.19 \%$ respectively); most of the infections in Turbo were detected by microscopy $(16 / 19,84.2 \%)$ and $93.75 \%(15 / 16)$ had malaria symptoms (Table 2); most of the infections were asymptomatic (temperature $\left.<37.5^{\circ} \mathrm{C}\right)$ and submicroscopic (9/11). In both towns, the higher prevalence of Plasmodium was found in indigenous communities.

\section{Association between Plasmodium infections and risk factors}


An analysis of the association of the subjects and household characteristics with Plasmodium infections is shown in Table 3. The prevalence of Plasmodium infections was higher in males (5.7\%) than females (2.9\%), with an alRR for the male sex of 2.38 (95\% Cl: $1.07-5.31$ ). People who have lived in the endemic region for more than four years had a higher prevalence of infection than those living in the endemic region for less time (4.2\% and $2.3 \%$, respectively). The infection was also higher in people with previous self-reported malaria as compared to people without malaria history (4.8\% and $3.2 \%$, respectively). Furthermore, living in an indigenous community increase the incidence rate of infection as compared to the non-indigenous population (aIRR 17.86, 95\% Cl: 2.12-150.19). Regarding household factors, it was found that participants without electricity services in their households have a higher rate of Plasmodium infection (aIRR 4.62, 95\% Cl: 1.89-11.32). The IRR could not be calculated for the association with water and sewage services (the convergence was not achieved in the GEE model); because none of the infected people had access to these services.

Due to living in an indigenous community as well as some characteristics of the houses were associated with a higher incidence rate of Plasmodium infections, a household description by indigenous and non-indigenous communities is detailed in Table 4 . A total of 125 from 212 houses were from indigenous communities (59\%), 30.4\% of these did not have electricity service, and $91.2 \%$ did not drain the standing water (91.2\%); these proportions were substantially higher in indigenous compared to non-indigenous communities.

\section{Discussion}

This study evaluated the prevalence of microscopic and submicroscopic Plasmodium infections in indigenous and non-indigenous communities from Antioquia, Colombia, and its associated factors, to describe the distribution of disease prevalence among heterogeneous populations; this knowledge is necessary to implement proper control strategies for each context [34]. We found that the prevalence of Plasmodium infections was higher in indigenous communities than in non-indigenous communities in both municipalities. Even more, all infections in El Bagre were detected in indigenous communities (11/11), and most of them were asymptomatic and submicroscopic (9/11). On the contrary, most of the infections in indigenous communities in Turbo were symptomatic and microscopic (84.2\%).

It is known that malaria in Colombia is characterized to have different transmission intensity in each endemic region [34]; in this way, our findings could be explained for differences in malaria profile in each municipality. Although the general prevalence of malaria in Antioquia has decreased during last years, the number of cases in El Bagre have been higher than in Turbo (from 190.45 cases/1000 people in 2007 to 21.29 cases/1000 people in 2017 in El Bagre and from 61.53 cases/1000 in 2007 to 0.77cases/1000 people in 2017 in Turbo).

As previously reported, malaria immunity is determined by previous Plasmodium exposure, where an anti-disease immunity is first achieved, and as a result, there is a reduction in severe malaria and mortality. Then, an anti-parasitic immunity is slowly acquired and confers protection against high parasitic densities, which in turn protect against the severe form of the disease [35]; this could explain the highest prevalence of submicroscopic infections in El Bagre, where 50.3\% of individuals had more than one malaria episode over life compared to $35.8 \%$ in Turbo (Supplementary table 1).. Nevertheless, we could not find an association of this variable with the Plasmodium infections using a GEE analysis. On the contrary, a previous study in Nariño Colombia showed that have suffered more than one malaria episode was associated with an increased risk of having asymptomatic infections (aOR 2.4, 95\% $\mathrm{Cl} 1.1-5.4$ ) [22]. These differences could be explained because our model included not only Asymptomatic but also symptomatic infections.

Household factors are also associated with malaria risk [36]. We found that had no access to electricity was associated with an increase in the malaria rate. These findings are in agreement with previous studies that reported that the poorest households had a $29 \%$ greater risk of microscopic parasitemia compared to the less poor houses (aRR 1,29; 95\% Cl 1,07-1,55) [37]. Additionally, lack of household electricity increased the childhood mortality in Rwanda, including malaria mortality (aOR: 1.4, 95\% Cl: 1.0-1.8) [38]. The above is important because housing quality can affect malaria risk through its effect on house entry of the malaria vector [37].

Taken together, the individual and housing characteristics could help to understand why the indigenous population has a higher prevalence than its counterpart non-indigenous does. Ethnicity is an important determinant of the health conditions of people, influencing morbidity and mortality rates in different ethnic groups and interfering with access to health services for certain population strata 2018 [39]. In Colombia, the exclusion of indigenous people is reflected in poverty rates, lack of land and employment, school desertion, unsatisfied basic needs, the access difficulty to health services, and an epidemiological profile where transmissible diseases exhibit a higher prevalence as than the general Colombian population. [40]. Furthermore, and due to the indigenous population frequently live close to rainforest or wetlands where they have more vector exposure, they have an increased risk of getting sick by vector-borne diseases such as malaria [8].

It is possible to suggest that the diversity of epidemic characteristics of malarial infection among the Colombia subpopulations account for an ideal environment for parasite evolution. In this environment, the parasite can interact at the same time with asymptomatic individuals and susceptible populations from different ethnics and under different public health interventions [34]. We suggest prevention efforts should be population-specific and vary according to the individual, housing, and environmental characteristics. Given the heterogeneity in the prevalence of malaria in Colombia, it is become necessary to target malaria control activities according to each population and context.

Page 5/16 
This study has some limitations. First, due to cross-sectional design, the association with malaria status should be interpreted with caution, as they do not imply causality. Second, it was no possible to analyze the risk factors for asymptomatic infections exclusively due to the low number of this kind of infection. This last could, in turn, affect the accuracy of confidence intervals for some of the factors analyzed due to the sample size. Third, as we mentioned before, the villages in this study were selected based on the historical records of malaria cases, the distance to the urban area, and the accessibility for field staff, and therefore and we did not make a random selection of the villages included in the study. The results of this study cannot be extrapolated to the general population; nevertheless, they are useful to exhibit the problems around the asymptomatic infections in the indigenous and non-indigenous people. Fourth, considering nowadays, there are ultra-sensitive molecular tests for the detection of low-density infections, the prevalence in this study could be underestimated due to the limit of detection of the nPCR used. By last, it is possible that other variables that we did not consider in the GEE model could explain the associated factors to Plasmodium infections. Future studies are required to improve the knowledge that we have about the risk factors of the plasmodium infections in indigenous communities. Despite these limitations, these results are useful to understand malaria transmission in studied places and to suggest prevention efforts according to the individual, housing, and environmental characteristics.

\section{Conclusion}

This study reveals that in both municipalities, most of the Plasmodium infections were in indigenous communities. Nevertheless, the infection profile was different for each town. A substantial proportion of asymptomatic and submicroscopic carriers were detected in El Bagre, while most of the symptomatic and microscopic infections were identified in Turbo. Our findings provide an understanding of the key characteristics of asymptomatic, submicroscopic, and microscopic infections in the study population: to live in an indigenous community, have previous malaria episodes and having no access to electricity, sewage system, and water services. The current malaria control efforts could benefit through the application of targeted interventions to indigenous villages using molecular tests to identify submicroscopic reservoirs that could be contributing to malaria transmission. Additionally, the identification of these infections not only in indigenous but also in the non-indigenous population, as well as demographic, social and household factors related to them, could help to implement specific malaria strategies for each context.

\section{List Of Abbreviations}

alRR: adjusted incident rate ratio; aOR: adjusted odds ratio; Cl: confidence interval; DNA: deoxyribonucleic acid; GEE: generalized estimating equation; IRR: incident rate ratio; IQR: inter quartile range; ITNs: insecticide-treated bed nets; $\mathrm{p} / \mu \mathrm{L}$ : parasite/ $\mu \mathrm{L}$ P. falciparum: Plasmodium falciparum; Plasmodium spp.:. Plasmodium species; P. vivax: Plasmodium vivax; PCR: polymerase chain reaction; $\mathrm{nPCR}$ : nested polymerase chain reaction; spp: species; UV: ultraviolet.

\section{Declarations}

\section{Ethical approval and consent to participate}

The study was reviewed and approved by the Facultad de Medicina Ethics Committee at the Universidad de Antioquia, Medellín, Colombia (Record 011 dated 28 July 2016). Before starting any study procedure, written informed consent or an informed assent in the case of participants under 18 years old were obtained from each participant. For participants < 18 years old additional informed consent from her parents or legal guardian was also obtained.

\section{Consent for publication}

Not applicable.

\section{Availability of data and materials}

The datasets used and/or analysed during the current study are available from the corresponding author on reasonable request.

\section{Competing interests}

The authors declare that they have no competing interests.

\section{Funding}


This study has been conducted with funding from Universidad de Antioquia (Code 2015-7765) and COLCIENCIAS (RC-075-2016, Code 111571249820).

\section{Authors' contributions}

JM, LZ, AT, CS, AV conceived the design of this study. JM and LZ supervised data collection and work field. JM, LZ and DA analysed the data. JM drafted the manuscript. All authors contributed to the manuscript edit, review and revising, and approved the final version of the manuscript.

\section{Acknowledgements}

The authors thank Hospital Francisco Valderrama in Turbo and Hospital Nuestra Señora del Carmen in El Bagre for their support in this research. A special thanks to the people from the communities for allowing and participating in this study, and to Deiber Toro, Rafael Mercado, Luisa Carbal Reyes y Veronica Sierra for its commitment in the fieldwork and to Juan Camilo Pérez for the molecular diagnostic.

\section{References}

1.Recht J, Siqueira AM, Monteiro WM, Herrera SM, Herrera S, Lacerda MVG: Malaria in Brazil, Colombia, Peru and Venezuela: current challenges in malaria control and elimination. Malar J 2017, 16.273.

2.World Health Organization. (2018). World malaria report 2018. World Health Organization. http://www.who.int/iris/handle/10665/275867.

3.Lindblade KA, Steinhardt L, Samuels A, Kachur SP, Slutsker L: The silent threat: asymptomatic parasitemia and malaria transmission. Expert Rev Anti Infect Ther 2013, 11:623-639.

4.Instituto Nacional de Salud. (2018). Informe de Evento Malaria, Colombia, 2018. Instituto Nacional de Salud [https://www.ins.gov.co/buscador-eventos/Informesdeevento/MALARIA_2018.pdf]

5.Organziación Panamerica de Salud (OPS). Informe de la situación de la Malaria en las Américas, 2014. Washington, D.C.

6.Coimbra CE, Santos RV, Welch JR, Cardoso AM, de Souza MC, Garnelo L, Rassi E, Follér ML, Horta BL: The First National Survey of Indigenous People's Health and Nutrition in Brazil: rationale, methodology, and overview of results. BMC Public Health 2013, 13:52.

7.Monje-Carvajal J: Colombian indigenous peoples' life plan, a structure of ethno-eco development. Luna Azul 2015, 41:29-56.

8.Ministerio de Salud y Protección Social, 2016. Perfil de Salud de la Población Indígena, y medición de desigualdades en salud. Colombia 2016. https://www.minsalud.gov.co/sites/rid/Lists/BibliotecaDigital/RIDE/VS/ED/PSP/Perfil-salud-pueblos-indigenas-colombia-2016.pdf

9.Coura JR, Suárez-Mutis M, Ladeia-Andrade S: A new challenge for malaria control in Brazil: asymptomatic Plasmodium infection-a review. Mem Inst Oswaldo Cruz 2006, 101.229-237.

10.Instituto Nacional de Salud; 2019. Comportamiento de la notificación malaria 2018. Boletín Epidemiológico semanal. Bogotá. http://www.ins.gov.co

11.Molina Gómez K, Caicedo MA, Gaitán A, Herrera-Varela M, Arce MI, Vallejo AF, Padilla J, Chaparro P, Pacheco MA, Escalante AA, et al: Characterizing the malaria rural-to-urban transmission interface: The importance of reactive case detection. PLoS Negl Trop Dis 2017, 11:e0005780.

12.Dirección Seccional de Salud de Antioquia. Eventos de interés en salud pública por subregiones y municipios. Antioquia $2007-2017$ /http://www.dssa.gov.co/index.php/estadisticas/eventos-en-salud-publica/item/71-eventos-de-interes-en-salud-publica-por-subregiones-ymunicipios-antioquia-2007-2012]

13.Castellanos A, Chaparro-Narváez P, Morales-Plaza CD, Alzate A, Padilla J, Arévalo M, Herrera S: Malaria in gold-mining areas in Colombia. Mem Inst Oswaldo Cruz 2016, 111:59-66.

14.Cohen JM, Moonen B, Snow RW, Smith DL: How absolute is zero? An evaluation of historical and current definitions of malaria elimination. Malar J 2010, 9.213.

15.Okell LC, Ghani AC, Lyons E, Drakeley CJ: Submicroscopic infection in Plasmodium falciparum-endemic populations: a systematic review and meta-analysis. J Infect Dis 2009, 200:1509-1517. 
16.Bousema T, Okell L, Felger I, Drakeley C: Asymptomatic malaria infections: detectability, transmissibility and public health relevance. Nat Rev Microbiol 2014, 12:833-840.

17.Carrasco-Escobar G, Miranda-Alban J, Fernandez-Miñope C, Brouwer KC, Torres K, Calderon M, Gamboa D, Llanos-Cuentas A, Vinetz JM: High prevalence of very-low Plasmodium falciparum and Plasmodium vivax parasitaemia carriers in the Peruvian Amazon: insights into local and occupational mobility-related transmission. Malar J 2017, 16:415.

18.Branch O, Casapia WM, Gamboa DV, Hernandez JN, Alava FF, Roncal N, Alvarez E, Perez EJ, Gotuzzo E: Clustered local transmission and asymptomatic Plasmodium falciparum and Plasmodium vivax malaria infections in a recently emerged, hypoendemic Peruvian Amazon community. Malar J 2005, 4.27.

19.Vallejo AF, García J, Amado-Garavito AB, Arévalo-Herrera M, Herrera S: Plasmodium vivax gametocyte infectivity in sub-microscopic infections. Malar J 2016, 15:48.

20.Vallejo AF, Chaparro PE, Benavides Y, Álvarez Á, Quintero JP, Padilla J, Arévalo-Herrera M, Herrera S: High prevalence of sub-microscopic infections in Colombia. Malar J 2015, 14:201.

21.Vásquez-Jiménez JM, Arévalo-Herrera M, Henao-Giraldo J, Molina-Gómez K, Arce-Plata M, Vallejo AF, Herrera S: Consistent prevalence of asymptomatic infections in malaria endemic populations in Colombia over time. Malar J 2016, 15:70.

22.Cucunubá ZM, Guerra Á, Rivera JA, Nicholls RS: Comparison of asymptomatic Plasmodium spp. infection in two malaria-endemic Colombian locations. Trans R Soc Trop Med Hyg 2013, 107:129-136.

23.Vásquez AM, Medina AC, Tobón-Castaño A, Posada M, Vélez GJ, Campillo A, González IJ, Ding X: Performance of a highly sensitive rapid diagnostic test (HS-RDT) for detecting malaria in peripheral and placental blood samples from pregnant women in Colombia. PLoS One 2018, 13:e0201769.

24.Rodríguez Vásquez C, Barrera Escobar S, Tobón-Castaño A: Low Frequency of Asymptomatic and Submicroscopic Plasmodial Infections in Urabá Region in Colombia. J Trop Med 2018, 2018:8506534.

25.Okell LC, Bousema T, Griffin JT, Ouédraogo AL, Ghani AC, Drakeley CJ: Factors determining the occurrence of submicroscopic malaria infections and their relevance for control. Nat Commun 2012, 3:1237.

26.Lin JT, Saunders DL, Meshnick SR: The role of submicroscopic parasitemia in malaria transmission: what is the evidence? Trends Parasitol 2014, 30:183-190.

27.Hofmann NE, Gruenberg M, Nate E, Ura A, Rodriguez-Rodriguez D, Salib M, Mueller I, Smith TA, Laman M, Robinson LJ, Felger I: Assessment of ultra-sensitive malaria diagnosis versus standard molecular diagnostics for malaria elimination: an in-depth molecular community crosssectional study. Lancet Infect Dis 2018, 18:1108-1116.

28.Alcaldía de Turbo - Antioquia. Indicadores del Municipio de Turbo. /http://www.turbo-antioquia.gov.co/indicadores.shtml\#poblacion] 29.Carmona-Fonseca J: La malaria en Colombia, Antioquia y las zonas de Urabá y Bajo Cauca: panorama para interpretar la falla terapéutica antimalárica. Parte 1. latreia 2003, 16.299-318.

30.Alcaldía de El Bagre - Antioquia. Información del Municipio [http://www.elbagre-antioquia.gov.co/Paginas/default.aspx]

31.Instituto Nacional de Salud (INS), Ministerio de Salud y Protección Social. Manual para el diagnóstico de malaria no complicada en puestos de diagnóstico y tratamiento. Milenio Editores, editor. Social Impresión 2015.

32.Singh B, Bobogare A, Cox-Singh J, Snounou G, Abdullah MS, Rahman HA: A genus-and species-specific nested polymerase chain reaction malaria detection assay for epidemiologic studies. Am J Trop Med Hyg 1999, 60:687-692.

33. Twisk J. Generalized estimating equations. In: Press CU, editor. Applied Longitudinal Data Analysis for Epidemiology. United States of America: Cambridge University Press; 2003.

34.Feged-Rivadeneira A, Ángel A, González-Casabianca F, Rivera C: Malaria intensity in Colombia by regions and populations. PLoS One 2018, 13:e0203673.

35.Marsh K, Kinyanjui S: Immune effector mechanisms in malaria. Parasite Immunol 2006, 28:51-60. 
36.Deressa W: Individual and household factors associated with ownership of long-lasting insecticidal nets and malaria infection in southcentral Ethiopia: a case-control study. Malar J 2017, 16:402.

37.Okiring J, Olwoch P, Kakuru A, Okou J, Ochokoru H, Ochieng TA, Kajubi R, Kamya MR, Dorsey G, Tusting LS: Household and maternal risk factors for malaria in pregnancy in a highly endemic area of Uganda: a prospective cohort study. Malar J 2019, 18:144.

38.Gupta N, Hirschhorn LR, Rwabukwisi FC, Drobac P, Sayinzoga F, Mugeni C, Nkikabahizi F, Bucyana T, Magge H, Kagabo DM, et al: Causes of death and predictors of childhood mortality in Rwanda: a matched case-control study using verbal social autopsy. BMC Public Health 2018, 18:1378.

39.Sandes LFF, Freitas DA, de Souza MFNS, Leite KBS: [Primary health care for South-American indigenous peoples: an integrative review of the literatureAtención primaria en salud a indígenas de América del Sur: revisión integrativa de la bibliografía]. Rev Panam Salud Publica 2018, 42:e163.

40.Hernández Sarmiento JM, Dávila Osorio VL, Martínez Sánchez LM, Restrepo Serna L, Grajales Ospina DC, Toro Montoya AE, Arango Urrea V, Vargas Grisales N, Estrada Gómez M, Lopera Valle JS, et al: Tuberculosis in indigenous communities of Antioquia, Colombia: epidemiology and beliefs. J Immigr Minor Health 2013, 15:10-16.

\section{Tables}

Table 1. Clinical and demographic characteristics and malaria history in the study population 


\begin{tabular}{|c|c|c|c|c|c|c|}
\hline \multirow[t]{2}{*}{ Characteristic } & \multicolumn{2}{|c|}{$\begin{array}{l}\text { Non-Indigenous } \\
\text { community } \\
\mathrm{n}=\mathbf{2 8 0}\end{array}$} & \multicolumn{2}{|c|}{$\begin{array}{c}\text { Indigenous } \\
\text { community } \\
n=433\end{array}$} & \multicolumn{2}{|c|}{$\begin{array}{l}\text { Total } \\
\mathrm{n}=713\end{array}$} \\
\hline & $\mathbf{n}$ & $\%$ & $\mathbf{n}$ & $\%$ & $\mathbf{n}$ & $\%$ \\
\hline \multicolumn{7}{|l|}{ Individual characteristics } \\
\hline Hemoglobin <11mg/dL & 43 & 15.4 & 55 & 12.7 & 98 & 13.7 \\
\hline \multicolumn{7}{|l|}{ Sex } \\
\hline Female & 145 & 51.8 & 234 & 54.0 & 379 & 53.2 \\
\hline \multicolumn{7}{|l|}{ Age } \\
\hline$<5$ & 27 & 9.6 & 43 & 9.9 & 70 & 9.8 \\
\hline $5-15$ & 87 & 31.1 & 133 & 30.7 & 220 & 30.9 \\
\hline$>15$ & 166 & 59.3 & 255 & 58.9 & 421 & 59.0 \\
\hline \multicolumn{7}{|l|}{ Occupation } \\
\hline Outdoor & 152 & 54.3 & 207 & 47.8 & 359 & 50.4 \\
\hline \multicolumn{7}{|l|}{ Residence time in endemic region } \\
\hline$\geq 5$ years & 210 & 75.0 & 314 & 72.5 & 524 & 73.5 \\
\hline \multicolumn{7}{|l|}{$\begin{array}{l}\text { Self-report of number of symptomatic malaria } \\
\text { episodes }\end{array}$} \\
\hline 0 & 106 & 37.9 & 173 & 40.0 & 279 & 39.1 \\
\hline 1 & 58 & 20.7 & 66 & 15.2 & 124 & 17.4 \\
\hline$>1$ & 116 & 41.4 & 194 & 44.8 & 310 & 43.5 \\
\hline Self-report of malaria last year & 12 & 4.3 & 51 & 11.8 & 63 & 8.8 \\
\hline \multicolumn{7}{|l|}{ Municipality } \\
\hline Turbo & 102 & 36.4 & 157 & 36.3 & 259 & 36.3 \\
\hline El Bagre & 178 & 63.6 & 276 & 63.7 & 454 & 63.7 \\
\hline Use of bed net & 262 & 93.6 & 405 & 93.5 & 667 & 93.5 \\
\hline \multicolumn{7}{|l|}{ Household characteristics } \\
\hline \multicolumn{7}{|l|}{ Number of inhabitants per household } \\
\hline $1-4$ & 127 & 45.4 & 162 & 37.4 & 289 & 40.5 \\
\hline$>5$ & 146 & 52.1 & 256 & 59.1 & 402 & 56.4 \\
\hline Participants who have animals in their households & 259 & 92.5 & 420 & 97.0 & 679 & 95.2 \\
\hline $\begin{array}{l}\text { Participants who draining standing water in their } \\
\text { households }\end{array}$ & 78 & 27.9 & 20 & 4.6 & 98 & 13.7 \\
\hline $\begin{array}{l}\text { Participants who have no access to electricity in their } \\
\text { households }\end{array}$ & 23 & 8.2 & 149 & 34.4 & 172 & 24.1 \\
\hline $\begin{array}{l}\text { Participants who have no access to water in their } \\
\text { households }\end{array}$ & 266 & 95.0 & 382 & 88.2 & 648 & 90.9 \\
\hline $\begin{array}{l}\text { Participants who have no access to sewage system in } \\
\text { their households }\end{array}$ & 271 & 96.8 & 415 & 95.8 & 686 & 96.2 \\
\hline
\end{tabular}


Table 2. Overall Plasmodium prevalence in the study population by diagnostic test.

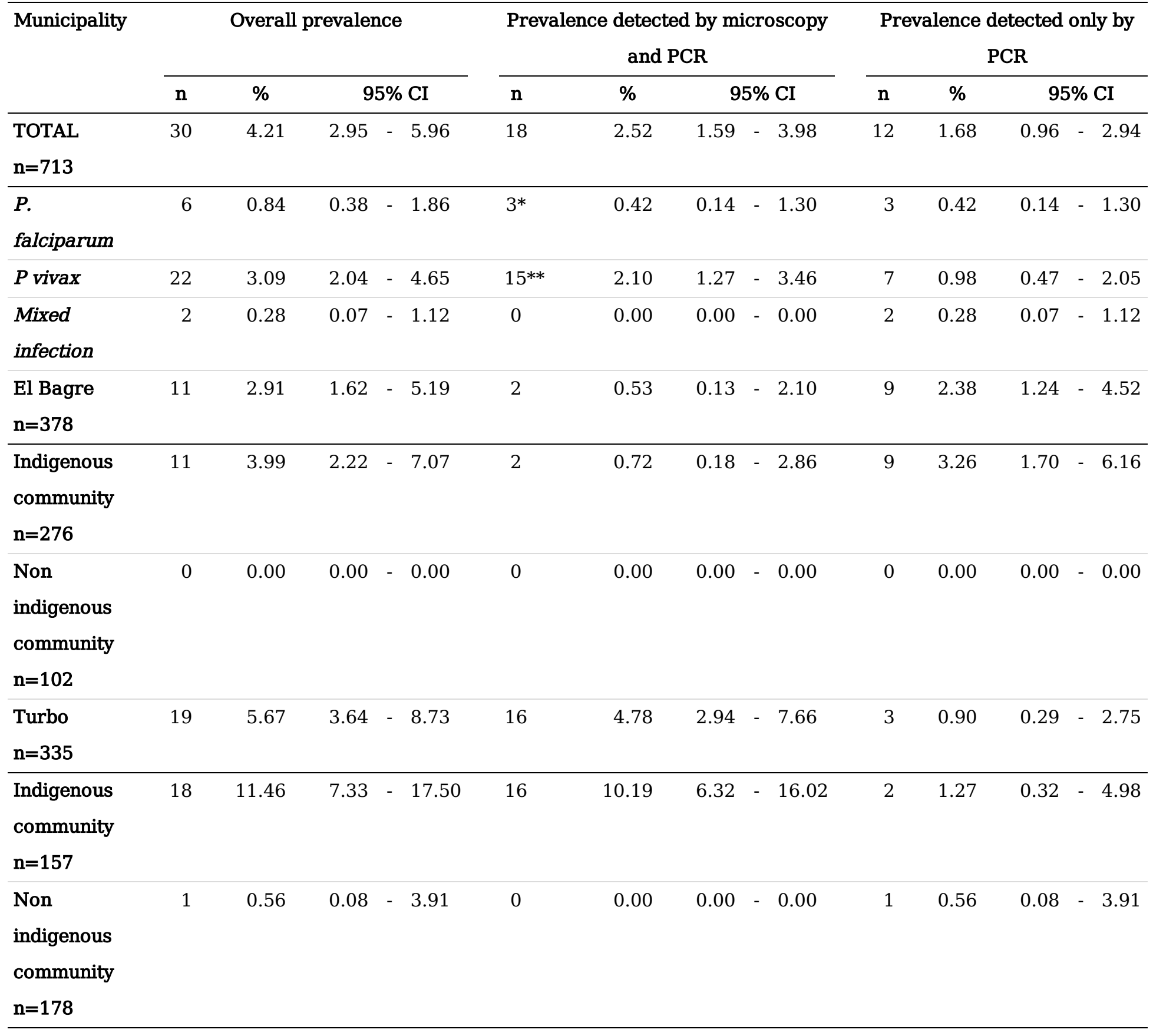

*Median parasitemia (IQR: inter quartile range) [parasites/ pl]) 360 (40-28186), ** Median parasitemia (IQR) [parasites/ pl]) $3147(2805-15615)$

Table 3. Association between individual and household characteristics with Plasmodium infections 


\begin{tabular}{|c|c|c|c|c|c|c|c|c|}
\hline \multirow[t]{3}{*}{ Characteristic } & \multicolumn{4}{|c|}{ Infected by Plasmodium } & \multicolumn{2}{|c|}{ Crude IRR* } & \multicolumn{2}{|c|}{ Adjusted IRR** } \\
\hline & \multicolumn{2}{|c|}{ No } & \multicolumn{2}{|c|}{ Yes } & \multirow[t]{2}{*}{ IRR } & \multirow[t]{2}{*}{ IC $95 \%$} & \multirow[t]{2}{*}{ IRR } & \multirow[t]{2}{*}{ IC $95 \%$} \\
\hline & $\mathbf{n}$ & $\%$ & $\mathbf{n}$ & $\%$ & & & & \\
\hline
\end{tabular}

\section{Individual factors}

\section{Sex}

Female

Male

Age

median (IQR)

$\begin{array}{cccc}20 & (10 & 17 & (11- \\ & -37) & & 29)\end{array}$

Age

$<5$

$5-15$

$\begin{array}{llll}67 & 95.7 & 3 & 4.3\end{array}$

1

1

$>15$

$\begin{array}{llll}209 & 95.0 & 11 & 5.0\end{array}$

$1.290 .36-4.61$

$0.930 .20-4.48$

$\begin{array}{llll}405 & 96.2 & 16 & 3.8\end{array}$

$0.94 \quad 0.27-3.22$

$0.68 \quad 0.15-3.07$

\section{Residence time in endemic region}

median (IQR)

$10 \quad(4-20) \quad 12 \quad(6-20)$

$1.00 \quad 0.97-1.03$

$1 \quad 0.97-1.03$

Residence time in endemic region

$\begin{array}{llllllllllll}<5 \text { years } & 172 & 97.7 & 4 & 2.3 & 1 & & 1 & \\ \geq 5 \text { years } & 502 & 95.8 & 22 & 4.2 & 1.64 & 0.57- & 4.70 & 1.83 & 0.55- & 6.08\end{array}$

Episodes number of symptomatic

malaria

median (IQR)

$1 \quad(0-3) \quad 2 \quad(0-4)$

$1.020 .99-1.06$

$1.010 .98-1.05$

Episodes number of symptomatic

malaria

\begin{tabular}{lllllllllll}
\hline 0 & 270 & 96.8 & 9 & 3.2 & 1 & \multicolumn{3}{c}{1} & \\
\hline 1 & 120 & 96.8 & 4 & 3.2 & 0.98 & $0.30-$ & 3.21 & 0.75 & $0.19-$ & 2.92 \\
\hline 1 & 293 & 94.5 & 17 & 5.5 & 1.77 & $0.78-$ & 4.03 & 1.55 & $0.59-$ & 4.10
\end{tabular}

\section{Self-report of malaria history}

0

$\geq 1$

$\begin{array}{cccc}270 & 96.8 & 9 & 3.2 \\ 413 & 95.2 & 21 & 4.8\end{array}$

1

1

Participants living in the indigenous community

\begin{tabular}{lcccccccc}
\hline No & 279 & 99.6 & 1 & 0.4 & 1 & 1 & \\
\hline Yes & 404 & 93.3 & 29 & 6.7 & 20.77 & $2.14-201.12$ & 17.86 & $2.12-150.19$ \\
\hline Use of bed net & & & & & & & & \\
\hline Yes & 638 & 95.7 & 29 & 4.3 & 1 & & 1 & \\
\hline No & 42 & 97.7 & 1 & 2.3 & 0.44 & $0.05-4.10$ & 0.51 & $0.06-4.14$ \\
\hline
\end{tabular}

\section{Household factors}

Number of inhabitants per household

median (IQR)

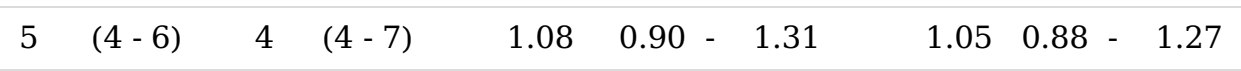


Number of inhabitants per household

$\begin{array}{llllllllllll}1-4 & 280 & 96.9 & 9 & 3.1 & 1 & & & & & \\ \geq 5 & 381 & 94.8 & 21 & 5.2 & 1.47 & 0.62 & -3.44 & 1.38 & 0.59- & 3.20\end{array}$

Participants who have animals in their households

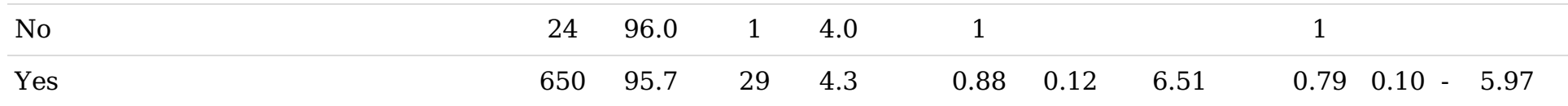

Participants who draining standing water in their households

\begin{tabular}{lcccccccccc}
\hline Yes & 97 & 99.0 & 1 & 1.0 & 1 & & 1 & \\
No & 577 & 95.2 & 29 & 4.8 & 3.99 & $0.48-32.88$ & 3.90 & 0.49 & 30.78
\end{tabular}

Participants who have access to electricity in their households

\begin{tabular}{lllllllllll}
\hline Yes & 518 & 97.7 & 12 & 2.3 & 1.00 & \multicolumn{3}{l}{1} \\
\hline No & 154 & 89.5 & 18 & 10.5 & 4.94 & 2.17 & 11.28 & 4.62 & $1.89-$ & 11.32
\end{tabular}

Participants who have access to water in their households

\begin{tabular}{lcccccc} 
Yes & 56 & 100.0 & 0 & 0.0 & 1 & 1 \\
\hline No & 618 & 95.4 & 30 & 4.6 & CNA $^{* * *}$ & CNA
\end{tabular}

Participants who have access to sewage system in their households

\begin{tabular}{lcccccc}
\hline Yes & 18 & 100.0 & 0 & 0.0 & 1 & 1 \\
\hline No & 656 & 95.6 & 30 & 4.4 & CNA & CNA \\
\hline
\end{tabular}

*Incidence Rate Ratio, **Adjusted by occupation and malaria last year, ***Convergence not achieved

Table 4. Household characteristics by indigenous and non-indigenous communities 


\begin{tabular}{|c|c|c|c|c|c|c|}
\hline \multirow{3}{*}{ Variable } & \multirow{2}{*}{\multicolumn{2}{|c|}{$\begin{array}{l}\text { Non Indigenous community } \\
\qquad \mathrm{n}=87\end{array}$}} & \multirow{2}{*}{\multicolumn{2}{|c|}{$\begin{array}{l}\text { Indigenous community } \\
\qquad \mathrm{n}=125\end{array}$}} & \multirow{2}{*}{\multicolumn{2}{|c|}{$\begin{array}{l}\text { Total } \\
\mathrm{n}=212\end{array}$}} \\
\hline & & & & & & \\
\hline & $\mathrm{n}$ & $\%$ & $\mathrm{n}$ & $\%$ & $\mathrm{n}$ & $\%$ \\
\hline \multicolumn{7}{|c|}{ Number of inhabitants } \\
\hline $1-4$ & 55 & 63.2 & 70 & 56.0 & 125 & 59.0 \\
\hline$>5$ & 31 & 35.6 & 51 & 40.8 & 82 & 38.7 \\
\hline \multicolumn{7}{|l|}{ Possession } \\
\hline Own & 79 & 90.8 & 113 & 90.4 & 192 & 90.6 \\
\hline Leased & 8 & 9.2 & 9 & 7.2 & 17 & 8.0 \\
\hline \multicolumn{7}{|l|}{ Electric service } \\
\hline Yes & 77 & 88.5 & 84 & 67.2 & 161 & 75.9 \\
\hline No & 9 & 10.3 & 38 & 30.4 & 47 & 22.2 \\
\hline \multicolumn{7}{|l|}{ Water service } \\
\hline Yes & 5 & 5.7 & 12 & 9.6 & 17 & 8.0 \\
\hline No & 82 & 94.3 & 110 & 88.0 & 192 & 90.6 \\
\hline \multicolumn{7}{|l|}{ Sewage system } \\
\hline Yes & 3 & 3.4 & 4 & 3.2 & 7 & 3.3 \\
\hline No & 84 & 96.6 & 118 & 94.4 & 202 & 95.3 \\
\hline \multicolumn{7}{|l|}{ Kind of water bodies } \\
\hline Lake & 3 & 3.4 & 2 & 1.6 & 5 & 2.4 \\
\hline Stagnant rain water & 6 & 6.9 & 3 & 2.4 & 9 & 4.2 \\
\hline River & 77 & 88.5 & 114 & 91.2 & 191 & 90.1 \\
\hline \multicolumn{7}{|c|}{ Fumigation (vector control program) } \\
\hline Yes & 78 & 89.7 & 115 & 92.0 & 193 & 91.0 \\
\hline No & 9 & 10.3 & 7 & 5.6 & 16 & 7.5 \\
\hline \multicolumn{7}{|l|}{ Use of insecticides } \\
\hline Yes & 5 & 5.7 & 10 & 8.0 & 15 & 7.1 \\
\hline No & 82 & 94.3 & 112 & 89.6 & 194 & 91.5 \\
\hline \multicolumn{7}{|c|}{ Draining standing water } \\
\hline Yes & 23 & 26.4 & 8 & 6.4 & 31 & 14.6 \\
\hline No & 64 & 73.6 & 114 & 91.2 & 178 & 84.0 \\
\hline
\end{tabular}

Figures 


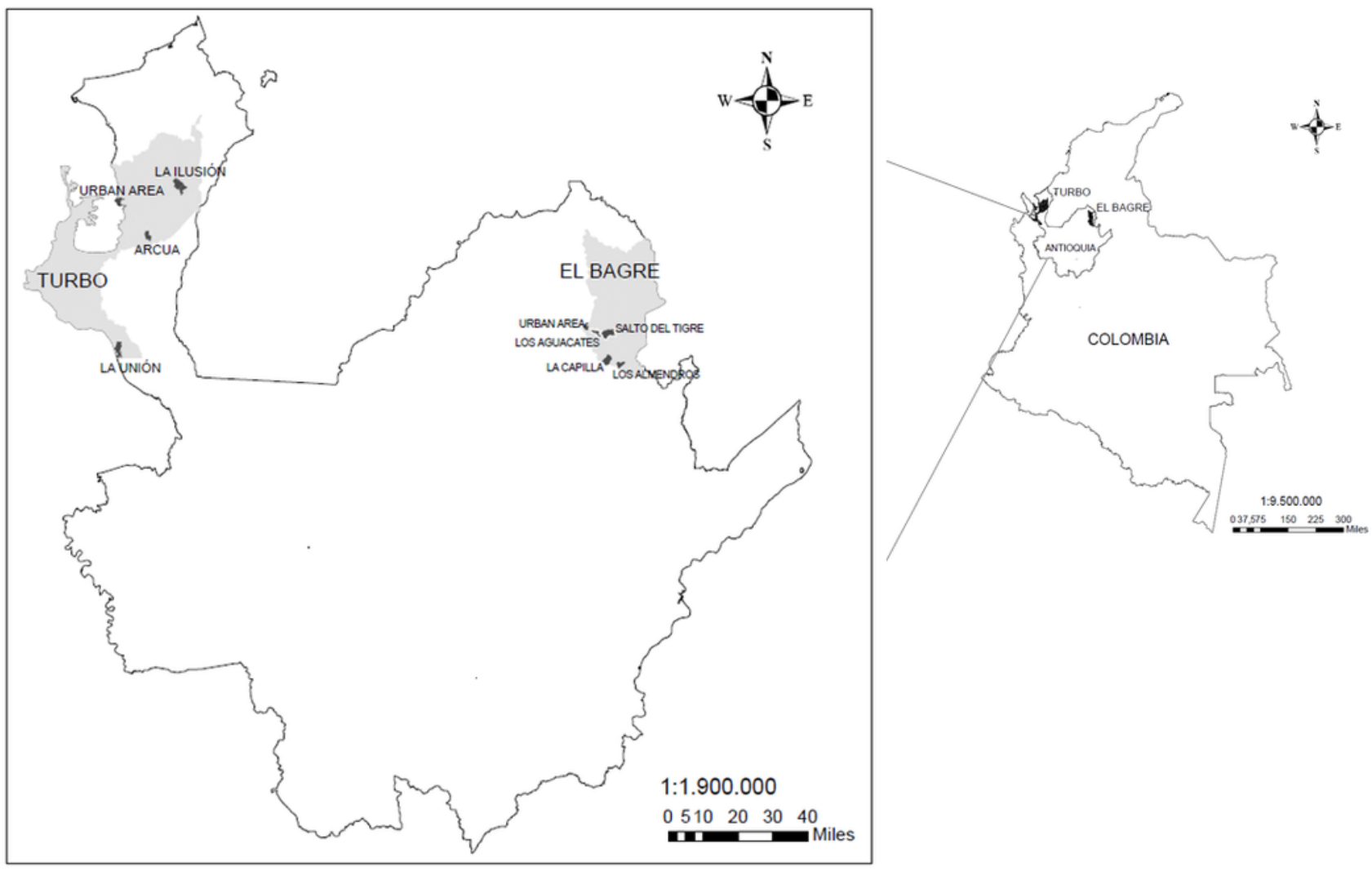

\section{Figure 1}

Study sites in Antioquia department, Colombia

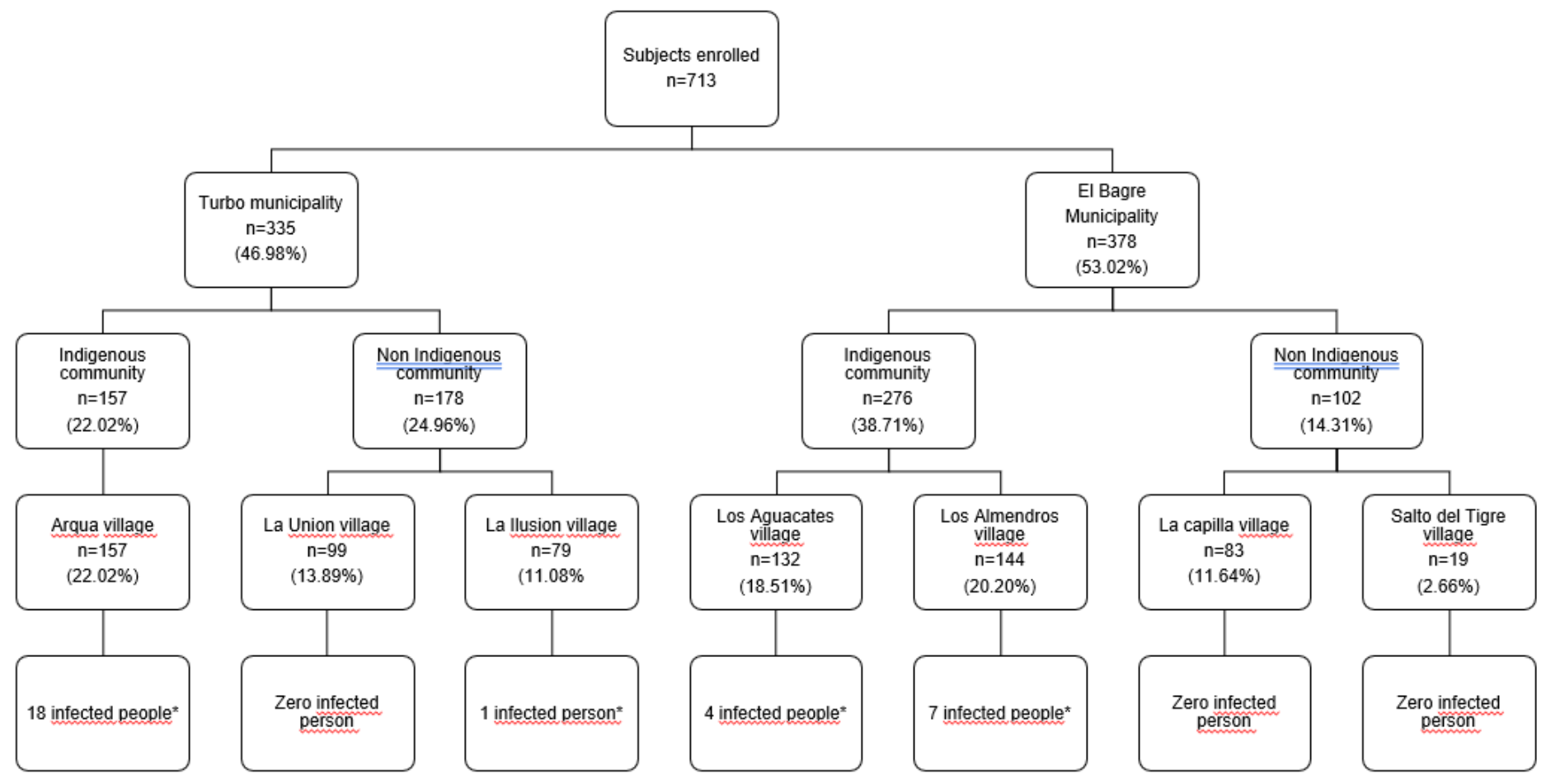

Figure 2

Flowchart of enrolled participants and proportion of infected people by villages. * Plasmodium infections detected by either microscopy or PCR

\section{Supplementary Files}


This is a list of supplementary files associated with this preprint. Click to download.

- Supplementarytable1.docx 